\title{
Evaluation of ease of intubation using C-MAC vs Macintosh laryngoscope in patients with the application of manual inline axial stabilization - A randomized comparative study.
}

\author{
M M Chandrashekaraiah ${ }^{I^{*}}, \mathrm{VH} \mathrm{Shah}^{2}, \mathrm{~V}$ C Pandey ${ }^{2}, \mathrm{~S} \mathrm{Adeel}^{3}$ \\ Registrar $^{I^{*}}$, Senior Registrar ${ }^{2}$, Consultant Anaesthetist ${ }^{3}$, Department of Anaesthesia and Pain Medicine, \\ King Hamad University Hospital, Bldg 2435 Road 2835 Area 228 Muharraq, Bahrain. \\ Corresponding author: drmcm@rediffmail.com
}

\begin{abstract}
Background and Aims: Endotracheal intubation in patients with cervical spine injury can be challenging particularly in the presence of manual in line stabilization. Video laryngoscopes can be used in these situations as their popularity is growing in the management of difficult airway and recently Difficult Airway Society (DAS) has included these devices in their algorithm.
\end{abstract}

\begin{abstract}
Methods: Sixty ASA 1 and 2 patients with normal airway requiring general anesthesia with endotracheal intubation were recruited for this randomized comparative simulative study. Neck was stabilized using manual inline axial stabilization maneuver and endotracheal intubation was carried out using either C-MAC or Macintosh laryngoscope. The following parameters were compared: intubation difficulty score (IDS), Cormack Lehane (CL) glottis view, heart rate (HR), systolic blood pressure (SBP), diastolic blood pressure (DBP) and mean arterial pressure (MAP). Hemodynamic parameters were noted at following intervals: pre-induction, pre intubation, immediate post intubation and 3 minutes after intubation. The data was analyzed using statistical tests Fischer exact test, Chi-square and independent two tailed student $t$ test
\end{abstract}

Results: Superior glottis view was observed in C-MAC group (CL-1: $56.7 \%$ vs 30\%, CL-2: $36.7 \%$ vs 56.7\%, CL-3: 6.7\% vs 10\%, CL-4: none vs 3.3\% in C-MAC and Macintosh group respectively). There was no difference in intubation difficulty score $(\mathrm{p}=0.822)$ and hemodynamic parameters also showed no clinical and statistical differences.

Conclusion: The present study shows good glottis view with C-MAC; although, IDS score is similar to conventional Macintosh laryngoscopy. The haemodynamic parameters are comparable in both groups. Overall, the C-MAC laryngoscope gives better glottis view indicating clinical significance.

Keywords: C-MAC laryngoscope; Macintosh laryngoscope; manual inline axial stabilization

\section{Introduction}

Use of video laryngoscopes in the management of difficult airway is on the surge as their role has been redefined in recently updated difficult airway society algorithm. ${ }^{1}$ In cervical spine (C-spine) injury, the standard positioning and intubation technique for direct laryngoscopy cannot be employed in order to minimize the cervical spine injury.,3,4 In our study, we are simulating a restricted neck movement by applying manual in line axial stabilization [MIAS] maneuver in patients requiring general anaesthesia with endotracheal intubation who have neither difficult airway nor Cspine injuries. The editorial published in
Anaesthesiology journal in 2012, emphasize the need for more randomized studies in order to establish clearly the benefits and advantages of the video laryngoscopes over the conventional laryngoscopes. ${ }^{5,6}$ The C-MAC ${ }^{\circledR}$ (Karl Storz Endoscopy, Tuttlingen, Germany) uses the same blade as conventional Macintosh laryngoscope except that, in the former the visualization of glottis is indirect on the video screen and the latter being direct. Even though, good view can be obtained in the indirect laryngoscopes, multiple attempts may be required for successful tracheal intubation. However, few studies contradict this. ${ }^{7-9}$ There is hardly any doubt that the advent of video assisted

(C) 2017. Chandrashekaraiah et al. This is an Open Access article distributed under the terms of the Creative Commons Attribution License (http: //creativecommons.org/licenses/by/4. 0), which permits unrestricted use, distribution, and reproduction in any medium, provided the original work is properly credited 
laryngoscopy technique has revolutionized the airway management. ${ }^{10}$

\section{Materials and methods}

After institutional ethics committee approval, sixty patients (group A- C-MAC 30 and group B Macintosh 30) undergoing elective surgery requiring general anesthesia with endotracheal intubation were recruited for this prospective randomized simulative study. Other criteria included ASA class 1 and 2, age 18 years to 65 years and no predictors of difficult airway. The exclusion criteria included previous neck surgery, unstable C-spine, trauma cases, obesity and emergency cases. Patients with previous burns, COPD, asthma and recent chest infections of less than 4 weeks were also excluded. The randomization was done using www.Randomization.com. All the patients underwent standardized anaesthetic technique that composed of pre-oxygenation with $100 \%$ oxygen for 3 minutes followed by induction with $2 \mathrm{mcg} / \mathrm{kg}$ fentanyl and propofol titrated to loss of verbal response. After assessing the adequacy of ventilation, all patients received $0.5 \mathrm{mg} / \mathrm{kg}$ atracurium. Trachea was intubated subsequently after three minutes of positive pressure ventilation with $100 \%$ oxygen and $2 \%$ sevoflurane. An assigned experienced anaesthetist did the laryngoscopy in order to avoid subjective bias. Before intubation, MIAS was applied by another trained anaesthetist. C-MAC or Macintosh laryngoscopes were used for intubation as per the randomization. Intubation Difficulty Scale score (IDS) as developed by Adnet ${ }^{11}$ was recorded by the laryngoscopist. HR, SBP, DBP and MAP were noted at the following intervals: pre-induction, preintubation, immediate post intubation and three minutes after intubation. The collected data was analyzed using appropriate statistical tests by statistician.

Statistical analysis: The sample size was calculated based on the previous studies of similar kind keeping power of study at $80 \%$ and alpha error at 5\%. The following statistical tests were used. Independent two-tailed student t test, Chi-square test and Fischer exact test.

\section{Results}

The demography and physical characteristics of the both groups did not have any statistical significance as depicted in Table 1.

Table 1: Demography and physical characteristics

\begin{tabular}{|l|l|l|l|}
\hline Features & $\begin{array}{l}\text { Group A } \\
\text { (C-MAC) }\end{array}$ & $\begin{array}{l}\text { Group B } \\
\text { (Macintosh) }\end{array}$ & $\begin{array}{l}\text { P } \\
\text { value }\end{array}$ \\
\hline Age $(\mathrm{yrs})$ & $36.43 \pm 11.48$ & $40.90 \pm 14.30$ & 0.183 \\
\hline $\begin{array}{l}\text { Sex } \\
(\mathrm{M} / \mathrm{F})\end{array}$ & $\mathrm{M}-17 ; \mathrm{F}-13$ & $\mathrm{M}-19 ; \mathrm{F}-11$ & 0.598 \\
\hline $\begin{array}{l}\text { Height } \\
(\mathrm{m})\end{array}$ & $1.66 \pm 0.11$ & $1.65 \pm 0.07$ & 0.642 \\
\hline $\begin{array}{l}\text { Weight } \\
(\mathrm{Kg})\end{array}$ & $74.90 \pm 17.82$ & $75.13 \pm 8.00$ & 0.949 \\
\hline $\begin{array}{l}\mathrm{BMI} \\
\left(\mathrm{kg} / \mathrm{m}^{2}\right)\end{array}$ & $27.03 \pm 5.21$ & $27.68 \pm 3.12$ & 0.558 \\
\hline
\end{tabular}

The airway evaluation in both groups did not differ much as illustrated in Table 2. Moreover, the Mallampati score (MP) also did not differ with $75 \%$ and $78 \%$ of MP 1 and 2 in group- A and group- B respectively. Rest comprised MP 3; in our study we did not come across MP 4 patients.

\begin{tabular}{|l|l|l|l|}
\hline Variables & $\begin{array}{l}\text { Group C- } \\
\text { MAC }\end{array}$ & $\begin{array}{l}\text { Group } \\
\text { Macintosh }\end{array}$ & P value \\
\hline $\begin{array}{l}\text { Mouth opening } \\
(\mathrm{cm})\end{array}$ & $4.70 \pm 0.68$ & $4.72 \pm 0.69$ & 0.926 \\
\hline TMD $(\mathrm{cm})$ & $6.88 \pm 0.81$ & $6.90 \pm 0.79$ & 0.936 \\
\hline $\begin{array}{l}\text { Neck } \\
\text { circumference } \\
(\mathrm{cm})\end{array}$ & $37.32 \pm 3.88$ & $34.75 \pm 3.97$ & 0.896 \\
\hline
\end{tabular}

Table 2: Airway examination

The Table 3 demonstrates the Cormack Lehane view obtained in both groups after application of MIAS manoeuver.

Table 3: Cormack Lehane score

\begin{tabular}{|l|l|l|}
\hline CL score & Group C-MAC & Group Macintosh \\
\hline CL-1 & $17(56.7 \%)$ & $9(30.0 \%)$ \\
\hline CL-2 & $11(36.7 \%)$ & $17(56.7 \%)$ \\
\hline CL-3 & $2(6.7 \%)$ & $3(10.0 \%)$ \\
\hline CL-4 & $0(0.0 \%)$ & $1(3.3 \%)$ \\
\hline Total & $30(100.0 \%)$ & $30(100.0 \%)$ \\
\hline
\end{tabular}

$\mathrm{P}=0.131$, Not significant (Positive association), Fisher Exact test

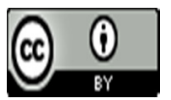

(C) 2017. Chandrashekaraiah et al. This is an Open Access article distributed under the terms of the Creative Commons Attribution License (http: //creativecommons.org/licenses/by/4. 0), which permits unrestricted use, distribution, and reproduction in any medium, provided the original work is properly credited 
Although together CL 1 and CL 2 grade remain nearly same in both groups $(93.4 \%$ - C-MAC, $86.7 \%$-Macintosh), we noted more of CL 1 $(56.7 \%)$ in C-MAC group in comparison to Macintosh (30.0\%) group, indicating the good view obtained with indirect laryngoscopy.

Table 4: Intubation Difficulty Scale score

\begin{tabular}{|l|l|l|l|l|}
\hline \multirow{2}{*}{ IDS $^{\mathbf{1 1}}$} & \multicolumn{2}{|l|}{$\begin{array}{l}\text { Group C } \\
\text { MAC }\end{array}$} & \multicolumn{2}{l|}{$\begin{array}{l}\text { Group } \\
\text { Macintosh }\end{array}$} \\
\cline { 2 - 5 } & No & \% & No & \% \\
\hline 0 ( No difficulty) & 8 & 26.7 & 7 & 23.3 \\
\hline $\begin{array}{l}\text { 0<IDS<5( slight } \\
\text { difficulty) }\end{array}$ & 20 & 66.7 & 19 & 63.3 \\
\hline $\begin{array}{l}>5 \text { ( moderate to } \\
\text { major difficulty) }\end{array}$ & 2 & 6.7 & 3 & 10 \\
\hline $\begin{array}{l}\text { Infinite (impossible } \\
\text { to intubate) }\end{array}$ & 0 & 0.0 & 1 & 3.3 \\
\hline Total & 30 & 100.0 & 30 & 100.0 \\
\hline
\end{tabular}

\section{$\mathrm{P}=0.822$, Not significant, Fisher Exact test}

Table 4 illustrates the IDS score of both groups. $26.7 \% \mathrm{v} / \mathrm{s} 23.3 \%$ showed no difficulty, slight difficulty was observed in $66.7 \% \mathrm{v} / \mathrm{s} 63.3 \%$, while moderate to major difficulty was faced in $6.4 \%$ vs $10 \%$, in C-MAC group and Macintosh group respectively $(p=0.822)$. In Macintosh group one patient matched the infinity criteria. This data indicates no statistical significance between the groups but clinically it may have great significance.

Table 5 depicts the haemodynamic parameters: HR. SBP, DBP and MAP that was recorded at the following time intervals: pre-induction, preintubation, immediate post intubation and three minute after intubation. There was no clinical significance as well as statistical significance between both groups. Although three minutes after intubation SBP reading was slightly high in CMAC group (C-MAC group; $114.77 \pm 20.81 \mathrm{~mm}$ of $\mathrm{Hg}$, Macintosh group; $106.50 \pm 12.12 \mathrm{~mm}$ of $\mathrm{Hg}, \mathrm{p}$ value- 0.065$)$, there was no clinical significance.
Table 5: Haemodynamic parameters

\begin{tabular}{|c|c|c|c|c|}
\hline \multicolumn{2}{|c|}{ Parameter } & Group A & Group B & $P$ value \\
\hline \multirow{4}{*}{$\begin{array}{l}\text { HR } \\
\text { beat } \\
\text { s/min }\end{array}$} & Pre induction & \multirow{2}{*}{$\begin{array}{l}83.00 \pm 14.03 \\
78.57 \pm 13.19\end{array}$} & $84.13 \pm 16.67$ & 0.777 \\
\hline & Pre-intubation & & $77.57 \pm 14.80$ & 0.783 \\
\hline & Post intubation & 86 & 90 & 0380 \\
\hline & $\begin{array}{l}\text { Post intubation } \\
3 \mathrm{~min}\end{array}$ & & & \\
\hline \multirow{5}{*}{$\begin{array}{l}\text { SBP } \\
\mathrm{mm} \\
\text { of } \mathrm{Hg}\end{array}$} & Pre induction & $132.43 \pm 13.76$ & $137.87 \pm 14.32$ & 0.139 \\
\hline & Pre-intubation & $100.83 \pm 14.60$ & $103.33 \pm 18.44$ & 0.563 \\
\hline & Post intubation & & \multirow{2}{*}{$129.53 \pm 19.86$} & \multirow{2}{*}{0.600} \\
\hline & Post ir & $126.40 \pm 25.82$ & & \\
\hline & $3 \mathrm{mi}$ & $114.77 \pm 20.81$ & $106.50 \pm 12.12$ & $0.065+$ \\
\hline \multirow{5}{*}{$\begin{array}{l}\text { DBP } \\
\mathrm{mm} \\
\text { of } \mathrm{Hg}\end{array}$} & Pre induction & \multirow[t]{2}{*}{$76.90 \pm 15.00$} & $78.37 \pm 14.57$ & 0.702 \\
\hline & Pre-intubation & & $61.57 \pm 15.61$ & 0.189 \\
\hline & Post intubation & \multirow{2}{*}{$75.97 \pm 16.44$} & & \\
\hline & Post intubation & & $75.10 \pm 14.53$ & 0.829 \\
\hline & & $66.67 \pm 16.48$ & $64.40 \pm 9.54$ & 0.517 \\
\hline \multirow{5}{*}{$\begin{array}{l}\text { MAP } \\
\mathrm{mm} \\
\text { of } \mathrm{Hg}\end{array}$} & Pre induction & \multirow{3}{*}{$\begin{array}{l}88.90 \pm 14.35 \\
65.23 \pm 13.94\end{array}$} & \multirow{3}{*}{$\begin{array}{l}92.63 \pm 13.44 \\
71.53 \pm 16.16\end{array}$} & 0.303 \\
\hline & Pre-intubation & & & (111 \\
\hline & Post intubation & & & \\
\hline & Post intubation & $88.10 \pm 17.11$ & $89.03 \pm 14.39$ & 0.820 \\
\hline & & $78.93 \pm 15.15$ & $75.17 \pm 9.17$ & 0.249 \\
\hline
\end{tabular}

\section{Discussion}

The introduction of video laryngoscope has helped anaesthetists and physicians to improve the management of difficult airways. In our study, we found that the CL score was superior in C-MAC group with no statistical significance. However, there was no difference in the IDS score between the two groups. In a study done by McElwain and Laffey ${ }^{11}$ on ninety patients with use of manual in line cervical stabilization, the Airtraq laryngoscope reduced the IDS score, improved the Cormack and Lehane glottis view. They also reported the reduced need for optimization manoeuvers in comparison with both the Macintosh and the C-MAC laryngoscopes. There were no differences in success rates or haemodynamic profiles post intubation between any of the devices tested. In their study, they used the preformed hockey stick shaped ET tube using a stylette for C-MAC group. We did not employ this technique, however in our study, if stylette was used then it was counted as an alternative attempt as per IDS developed by 
Adnet. ${ }^{12}$ In another similar study done by Gupta ${ }^{13}$ et al, IDS scores between C-MAC and Macintosh group were no different. This correlates with our finding; however, Gupta et al used two types of endotracheal tube assembly (one with stylette and the other without), they found IDS score and mean intubation duration was significantly less in CMAC stylette endotracheal tube group. However, in our study we considered using stylette as an additional adjunct. In addition, we did not compare the time duration for successful intubation. Aziz ${ }^{8}$ et al compared C-MAC and Macintosh laryngoscope in suspected difficult airway scenarios. Their study revealed higher success rate with C-MAC, lesser use of adjuncts and external maneuver in C-MAC group; however, the failure rate was no different between the two despite good glottis view. In our study with simulated C-spine stabilization in normal airway, we found no significant difference in IDS scores and airway manipulation in both groups. Akbar et $\mathrm{al}^{14}$ did a similar study, but they did not use IDS scale. They employed some different assessment parameters like intubation attempts, CL grades, optimization manoeuvers and complications. They concluded better CL grade with C-MAC with statistical significance. They also noted no difference in haemodynamics in both groups. Our study partially supports this study as we found better CL grades but we were unable to find any statistical significance in the IDS score. The systematic review of video laryngoscopy in successful oro-tracheal intubations done by Healy et $\mathrm{al}^{15}$ gathered limited information regarding the benefits of video-laryngoscopy over conventional method; yet, they recommended use of Airtraq, CTrach, Glide Scope, Pentax AWS, and V-MAC to achieve successful intubation in difficult airway and in failed intubation cases. Recent systematic review and meta-analysis of available alternative techniques of intubation versus conventional Macintosh laryngoscope with cervical spine immobilsation done by Suppan et $\mathrm{al}^{16}$ revealed that only Airtraq device had shown its usefulness in patients with C-spine immobilization, in comparison to conventional direct laryngoscope.

\section{Conclusion}

The cervical spine immobilization using MIAS manoeuver is one of the recognized techniques in preventing further damage to spinal cord during Cspine injuries. Nonetheless, it leads to difficulty in airway management. The present study shows positive correlation in getting good glottis view with C-MAC. However, IDS score was comparable to conventional Macintosh group reflecting no statistical significance. In our study we did not see much difference in haemodynamic changes except three-minute post intubation, SBP was slightly low in Macintosh group with statistical but no clinical significance.

\section{Speculation}

The era of video-laryngoscopes has started. The ease of use as a teaching aid and for managing difficult airways cannot be undermined anymore. The recent updated DAS guidelines included these devices in the first step itself. Some degree of practice is required with these devices. The increased usage of video-laryngoscopes in coming days is beyond any doubt.

\section{Key message}

Introduction of video-laryngoscopes in clinical practice has changed the approach in managing the difficult airway. Although, consensus recommendation is lacking; yet, it is definitely a useful alternative for conventional laryngoscope. The updated DAS algorithm has included this device in the initial step.

\section{References}

1. Frerk C, Mitchell VS, McNarry AF et al. Difficult Airway Society 2015 guidelines for management of unanticipated difficult intubation in adults. Br. J. Anaesth 2015 Dec;115(6):827-48 http://dx.doi.org/10.1093/bja/aev371 PMid:26556848 PMCid:PMC4650961

2. Como JJ, Diaz JJ. Dunham CM et al. Cervical spine injuries following trauma. Jou Trauma.2009; 67 (3): 651-9.

http://dx.doi.org/10.1097/TA.0b013e3181ae583b PMid:19741415

3. New Zealand Resuscitation council and Australian Resuscitation Council Guideline 9.1.6 Jan 2016 pp 1-6. (https://resus.org.au/guidelines/ anzcorguideline-9-1-6-spinal-jan16. pdf Accessed 20/05/16)

4. Benger J, Blackham J. Why Do We Put Cervical Collars On Conscious Trauma Patients?

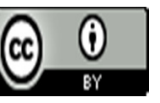

(c) 2017. Chandrashekaraiah et al. This is an Open Access article distributed under the terms of the

Creative Commons Attribution License (http: //creativecommons.org/licenses/by/4. 0), which permits unrestricted use, distribution, and reproduction in any medium, provided the original work is properly credited 
Scandinavian Journal of Trauma, Resuscitation and Emergency Medicine. 2009;17:44.

(doi:10.1186/1757-7241-17-44).

http://dx.doi.org/10.1186/1757-7241-17-44

5. Sakles JC, Mosier J, Chiu S et al. A Comparison of the C-MAC Video Laryngoscope to the Macintosh Direct Laryngoscope for Intubation in the Emergency Department. Annals of Emergency Medicine 2012; 60 (6): 739-748.

http://dx.doi.org/10.1016/j.annemergmed.2012.03. $\underline{031}$

PMid:22560464 PMCid:PMC4532403

6. Takashi A. Video laryngoscopes Do they truly have roles in difficult airways. Anesthesiology 2012; 116:515-7.

http://dx.doi.org/10.1097/ALN.0b013e318246e866 PMid:22261794

7. Healy DW, Picton P, Morris M, Turner C. Comparison of the glidescope, CMAC Storz DCI with the Macintosh laryngoscope during simulated difficult laryngoscopy: a manikin study. BMC Anesthesiology 2012; 12:11

http://dx.doi.org/10.1186/1471-2253-12-11

PMid:22720884 PMCid:PMC3519500

8. Aziz MF, Dillman D, Fu R, Brambrink AM. Comparative effectiveness of the C-MAC video laryngoscope versus direct laryngoscopy in the setting of the predicted difficult airway. Anesthesiology. $2012 \quad$ Mar;116(3):629-36. http://dx.doi.org/10.1097/ALN.0b013e318246ea34 PMid:22261795

9. Serocki G, Neumann T, Scharf E et al. Indirect video laryngoscopy with C-MAC D-Blade and GlideScope: a randomized, controlled comparison in patients with suspected difficult airways. Minerva Anestesiol.2013Feb;79(2):121-9.

PMid:23032922

10. James CD, Micheal $H$. Direct and video laryngoscope using Mac Grath MAC direct enhanced laryngoscope. http://www.anesthesiologynews.com/download/SR 1324_WM .pdf: Aug 2013

11. Adnet F, Stephen WB, Stephane XR et al. The intubation difficulty scale. Proposing and evaluation of new score characterizing the complexity of endotracheal intubation. Anesthesiology 1997; 87: 1290-7.

http://dx.doi.org/10.1097/00000542-199712000-

00005

PMid:9416711

12. McElwain J, Laffey JG. Comparison of the CMAC®, Airtraq ${ }^{\circledR}$, and Macintosh laryngoscopes in patients undergoing tracheal intubation with cervical spine immobilization. Br J Anaesth. 2011 ; 107(2):258-64

http://dx.doi.org/10.1093/bja/aer099

PMid:21586444

13. Gupta N, Prasad G, Prabhakar RH. Clinical evaluation of C-MAC video laryngoscope with or without use of stylet for endotracheal intubation in patients with cervical spine immobilization. Journal ofAnesthesia2013;27(5):663-670.

http://dx.doi.org/10.1007/s00540-013-1588-6 PMid:23475442

14. Akbar SH, Ooi JS. Comparison between CMAC video-laryngoscope and Macintosh direct laryngoscope during cervical spine immobilization. Middle East J Anesthesia 2015 Feb;23(1):43-50.

15. Healy DW, Maties O, Hovord D, Kheterpal S. A systematic review of the role of video laryngoscopy in successful orotracheal intubation. BMC Anesthesiology 2012; 12:32. http://dx.doi.org/10.1186/1471-2253-12-32 PMid:23241277 PMCid:PMC3562270

16. Suppan L, Tramèr MR, Niquille $M$ et al. Alternative intubation techniques vs Macintosh laryngoscopy in patients with cervical spine immobilization: systematic review and meta-analysis of randomized controlled trials. Br J Anaesth. 2016 ;116(1):27-36 http://dx.doi.org/10.1093/bja/aev205

PMid:26133898 PMCid:PMC4681615

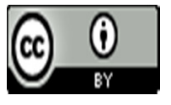

(c) 2017. Chandrashekaraiah et al. This is an Open Access article distributed under the terms of the Creative Commons Attribution License (http: //creativecommons.org/licenses/by/4. 0), which permits unrestricted use, distribution, and reproduction in any medium, provided the original work is properly credited 